\title{
Changes of cerebrospinal fluid in the upper neck area with age using diffusion weighted MR imaging
}

\author{
Ichiro Ogura*, Takaaki Oda, Mikiko Sue, Yoshihiko Sasaki \\ Radiology, The Nippon Dental University Niigata Hospital, Chuo-ku, Niigata, Japan
}

Received: November 20, 2017

DOI: $10.5430 /$ ijdi.v5n1p20
Accepted: January 9, 2018

Online Published: January 24, 2018

\begin{abstract}
Purpose: Few studies have concerned the absolute apparent diffusion coefficient (ADC) values in the normal cerebrospinal fluid in the upper neck area and the effect of aging on diffusion. The purpose of this study was to evaluate changes of cerebrospinal fluid in the upper neck area with age using diffusion weighted MR imaging (DWI).

Methods and methods: Our study included 160 patients who underwent MR imaging for oral and maxillofacial diseases. All patients were examined by DWI with $2 \mathrm{~b}$ values $\left(0\right.$ and $\left.800 \mathrm{sec} / \mathrm{mm}^{2}\right)$ at 1.5 Tesla and ADC maps. The cerebrospinal fluid and spinal cord in the upper neck area were analyzed using the ADC values and age.

Results: ADC value of cerebrospinal fluid was significantly correlated to ADC value of spinal cord $\left(R^{2}=0.141, p=.000\right)$. ADC value of spinal cord had no relation to age $\left(R^{2}=0.015, p=.125\right)$. ADC value of cerebrospinal fluid had significant relation to age $\left(R^{2}=0.026, p=.042\right)$.

Conclusions: We indicated the changes of cerebrospinal fluid in the upper neck area with age using DWI. The data reported herein are representative, and the ADC values can be used for reference in future studies and in clinical settings.
\end{abstract}

Key Words: Diffusion magnetic resonance imaging, Spinal cord, Cerebrospinal fluid, Aging

\section{INTRODUCTION}

Studies of cerebrospinal fluid analyses may provide biomarkers for dementia sub-typing and also may provide clues about brain disease pathogenesis. ${ }^{[1]}$ These biomarker studies are even more important as there are clearly many diseases in addition to Alzheimer's disease that underlie the clinical syndrome of dementia. ${ }^{[2]}$ Moreover, neuroradiology suggest a strong relationship between amyotrophic lateral sclerosis progression and spinal cord atrophy by MR imaging. ${ }^{[3]}$

Diffusion weighted MR imaging (DWI) is a fast sequence constructed from fast advanced spin echo and echo-planar imaging (EPI). ${ }^{[4]}$ DWI allows a quantitative index of water diffusivity for each voxel that provides visualization of the microscopic motion of water molecules within tissues. ${ }^{[5]}$ Furthermore, some reports showed the application of DWI with calculation of apparent diffusion coefficient (ADC) in the differentiation between malignant and benign diseases in head and neck. ${ }^{[6-10]}$

Studies regarding absolute ADC values in the normal human brain and the effect of aging on diffusion are scarce, and only a few reports involving small numbers of subjects have been published. ${ }^{[11]}$ Moreover, age is an important factor for spinal cord injury and repair. ${ }^{[12,13]}$ However, to the best of our knowledge, there are not clear studies in the changes of cerebrospinal fluid in head and neck with age using DWI. We evaluated the changes of cerebrospinal fluid in the upper

\footnotetext{
*Correspondence: Ichiro Ogura; Email: ogura@ngt.ndu.ac.jp; Address: Radiology, The Nippon Dental University Niigata Hospital, 1-8 Hamauracho, Chuo-ku, Niigata, Japan.
} 
neck area with age using DWI.

\section{Patients and methods}

Our study included 160 patients ( 80 male, 80 female; aged 8-90 years, mean age 63.6 years) who had MR imaging for oral and maxillofacial diseases at The Nippon Dental University Niigata Hospital from October 2016 to May 2017 after providing written informed consent.

All patients were examined using a MR unit with a head coil
(EXCELART; Toshiba, Japan) by DWI with 2 b values ( 0 and $800 \mathrm{sec} / \mathrm{mm}^{2}$ with an EPI sequence) at 1.5 Tesla. The following technical parameters were used: TR $8476 \mathrm{msec}$, TE 80 msec. The ADC maps were automatically computed from the DWI with $b=800 \mathrm{sec} / \mathrm{mm}^{2}$ (see Figure 1). Two oral and maxillofacial radiologists used $\mathrm{ROI}$ to compute the ADC values of ADC maps. Furthermore, 3 ROIs by similar size from the spinal cord and cerebrospinal fluid in the upper neck area to obtain a mean ADC value were measured.
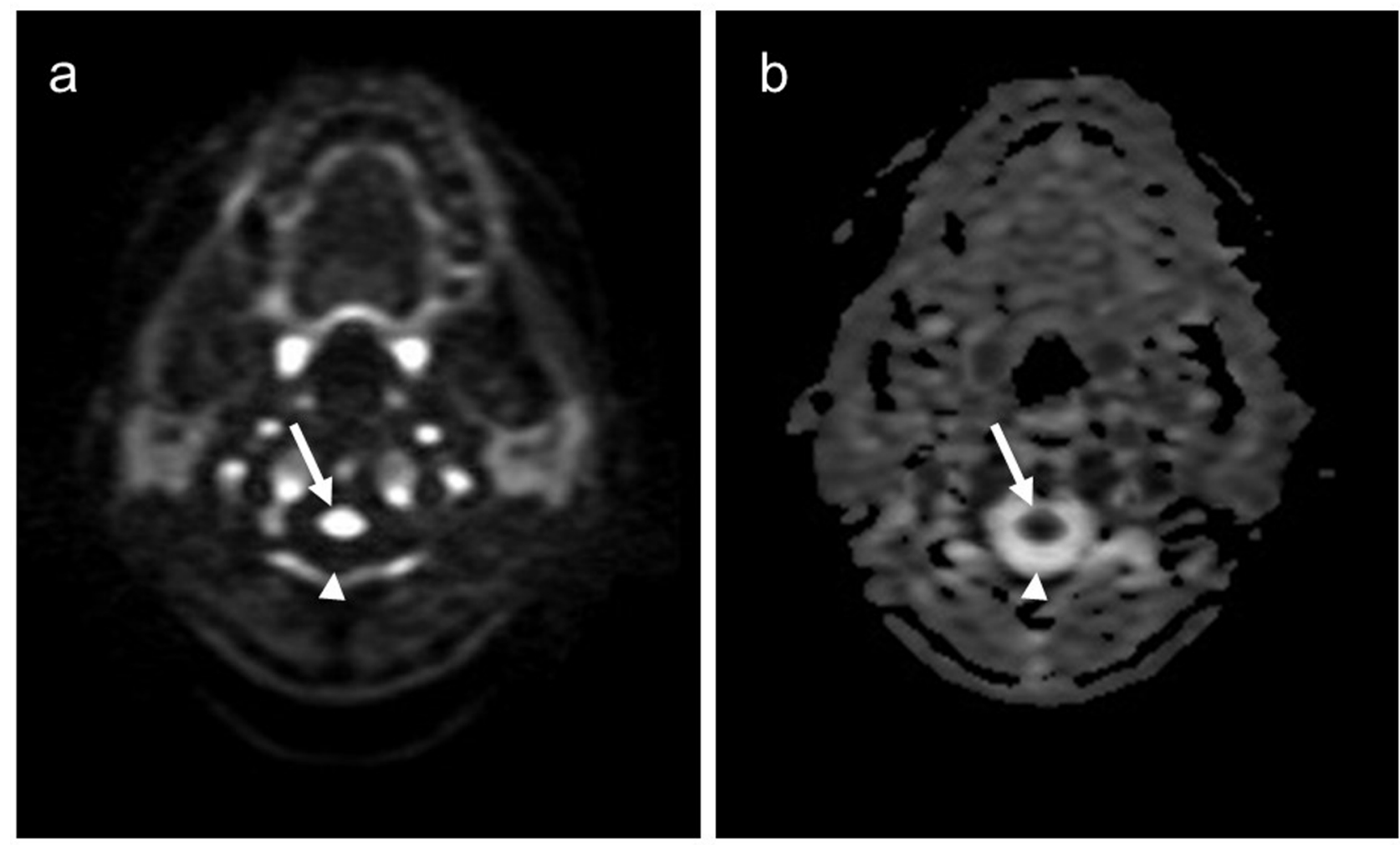

Figure 1. Normal structures in a 25-year-old female. (a) Diffusion-weighted image shows the spinal cord (arrow) and cerebrospinal fluid (arrowhead). (b) Apparent diffusion coefficient (ADC) map shows the spinal cord (arrow) and cerebrospinal fluid (arrowhead).

The relationship between age, ADC value of spinal cord, cerebrospinal fluid and gender was compared by MannWhitney U test. Furthermore, the relationship between ADC value in spinal cord, cerebrospinal fluid and age was assessed by Pearson's rank correlation test. A $p$ value $<.05$ was considered significant.

\section{Results}

The ADC values of spinal cord and cerebrospinal fluid are shown in Table 1. Regarding gender, the mean ADC value of the spinal cord was not statistically significant difference between male $\left(0.73 \pm 0.19 \times 10^{-3} \mathrm{~mm}^{2} / \mathrm{sec}\right)$ and female $\left(0.75 \pm 0.19 \times 10^{-3} \mathrm{~mm}^{2} / \mathrm{sec}\right)$. Furthermore, the mean
ADC value of the cerebrospinal fluid was not statistically significant difference between male $\left(3.66 \pm 0.54 \times 10^{-3}\right.$ $\left.\mathrm{mm}^{2} / \mathrm{sec}\right)$ and female $\left(3.62 \pm 0.56 \times 10^{-3} \mathrm{~mm}^{2} / \mathrm{sec}\right)$.

ADC value of spinal cord had no relation to age $\left(R^{2}=0.015\right.$, $p=.125$, see Figure 2). ADC value of cerebrospinal fluid had significantly relation to age $\left(R^{2}=0.026, p=.042\right.$, see Figure 3$)$. Furthermore, ADC value of cerebrospinal fluid was significantly correlated to ADC value of spinal cord $\left(R^{2}\right.$ $=0.141, p=.000$, see Figure 4).

\section{Discussion}

Paucity of changes of spinal cord and cerebrospinal fluid with age using DWI warranted this study. 
Table 1. ADC values of spinal cord and cerebrospinal fluid in the upper neck area

\begin{tabular}{llll}
\hline & Male & Female & $\boldsymbol{p}$ value \\
\hline $\begin{array}{l}\text { Number } \\
\text { Age (years) }\end{array}$ & 80 & 80 & \\
Mean \pm SD & $64.1 \pm 14.7$ & $63.2 \pm 18.8$ & .663 \\
Range & $25-87$ & $8-90$ & \\
ADC value of spinal cord $\left(\times \mathbf{1 0}^{-3} \mathbf{~ m m}^{2} \mathbf{s}^{-1}\right)$ & & \\
Mean \pm SD & $0.73 \pm 0.19$ & $0.75 \pm 0.19$ & .481 \\
Range & $0.31-1.29$ & $0.30-1.10$ & \\
ADC value of cerebrospinal fluid $\left(\times \mathbf{1 0}^{-3} \mathbf{~ m m}^{2} \mathbf{s}^{-\mathbf{1}}\right)$ & & .611 \\
Mean \pm SD & $3.66 \pm 0.54$ & $3.62 \pm 0.56$ & \\
Range & $2.69-4.67$ & $2.49-4.82$ & \\
\hline
\end{tabular}

Note. ADC, apparent diffusion coefficient; SD, standard deviation.

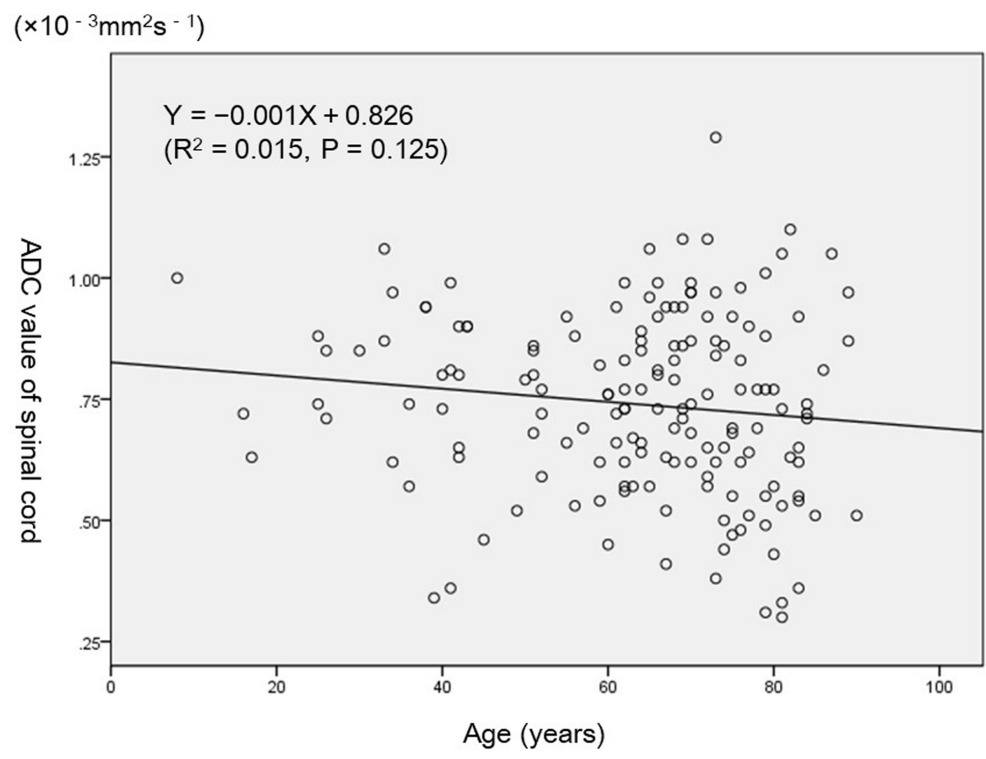

Figure 2. Scatter diagram shows the relationship between age and ADC value of spinal cord

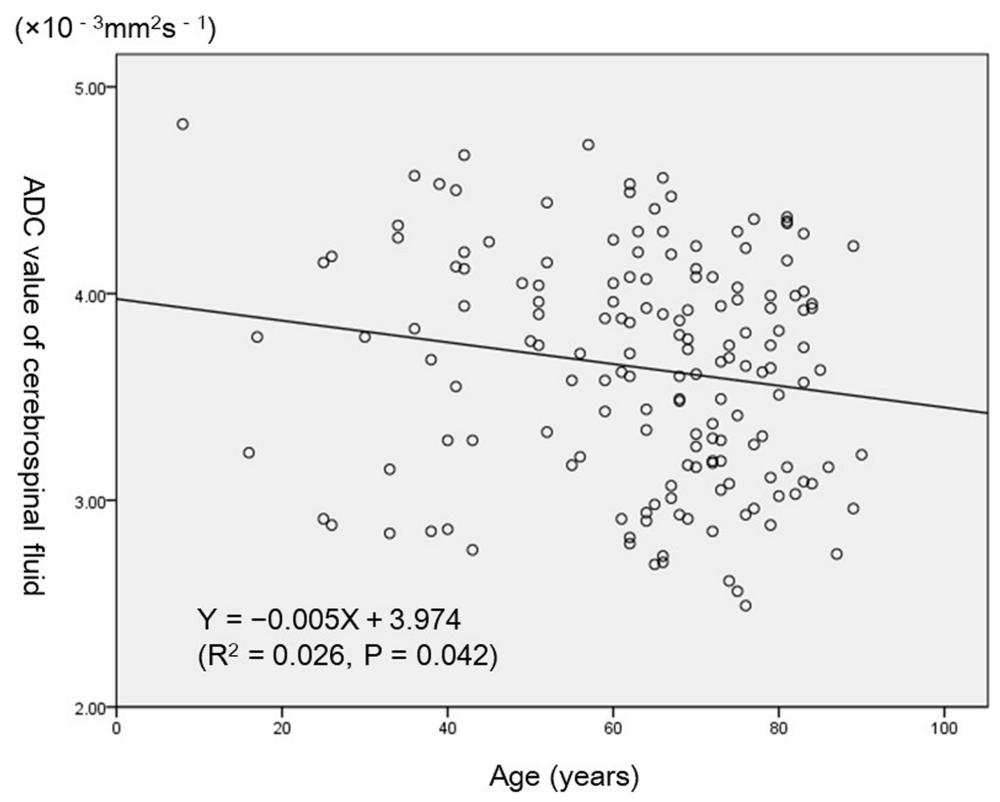

Figure 3. Scatter diagram shows the relationship between age and ADC value of cerebrospinal fluid 


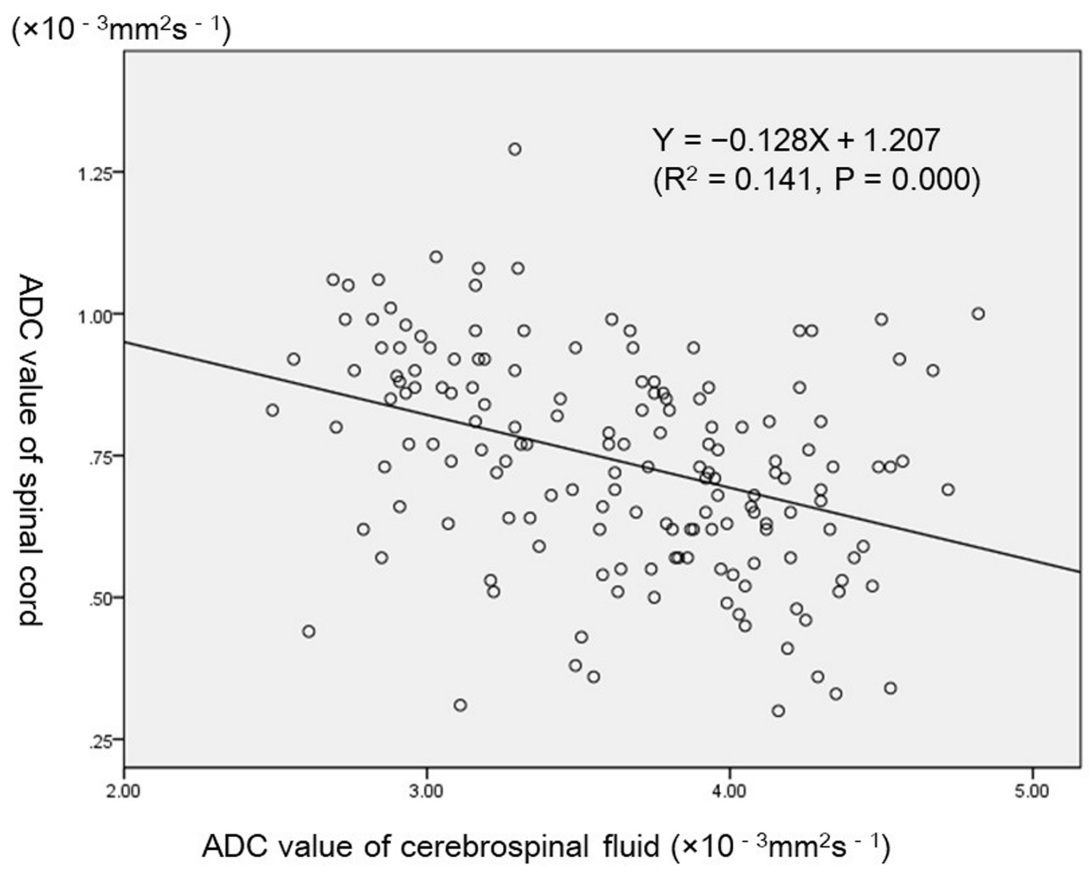

Figure 4. Scatter diagram shows the relationship between ADC value of cerebrospinal fluid and spinal cord

Regarding ADC values of the normal human brain, Helenius et al. ${ }^{[11]}$ indicated that the cortical gray matter $(0.89 \pm$ $\left.0.04 \times 10^{-3} \mathrm{~mm}^{2} / \mathrm{sec}\right)$ were highest, the deep gray matter $\left(0.75 \pm 0.03 \times 10^{-3} \mathrm{~mm}^{2} / \mathrm{sec}\right)$ were lower, and the white matter $\left(0.70 \pm 0.03 \times 10^{-3} \mathrm{~mm}^{2} / \mathrm{sec}\right)$ were lowest. Furthermore, no difference was observed between female and male. Regarding our study, the mean ADC value in the spinal cord was not statistically significant difference between male $\left(0.73 \pm 0.19 \times 10^{-3} \mathrm{~mm}^{2} / \mathrm{sec}\right)$ and female $(0.75 \pm 0.19$ $\times 10^{-3} \mathrm{~mm}^{2} / \mathrm{sec}$ ). Furthermore, the mean ADC values of the cerebrospinal fluid were not statistically significant difference between male $\left(3.66 \pm 0.54 \times 10^{-3} \mathrm{~mm}^{2} / \mathrm{sec}\right)$ and female $\left(3.62 \pm 0.56 \times 10^{-3} \mathrm{~mm}^{2} / \mathrm{sec}\right)$. We consider that no difference was observed between female and male in ADC value of normal human brain, spinal cord and cerebrospinal fluid. Furthermore, this study showed the deep gray matter $\left(0.75 \pm 0.03 \times 10^{-3} \mathrm{~mm}^{2} / \mathrm{sec}\right)$ and the white matter $(0.70 \pm$ $0.03 \times 10^{-3} \mathrm{~mm}^{2} / \mathrm{sec}$ ) were similar to the spinal cord (male: $0.73 \pm 0.19 \times 10^{-3} \mathrm{~mm}^{2} / \mathrm{sec}$, female: $0.75 \pm 0.19 \times 10^{-3}$ $\left.\mathrm{mm}^{2} / \mathrm{sec}\right)$.

Helenius et al. ${ }^{[11]}$ showed that ADC values increase with age was found in the lateral ventricles, and the ADC values in the thalami in 65-85 years group were significantly larger than in those of the other age groups. The authors showed that ADC value of spinal cord had no relation to age $\left(R^{2}\right.$ $=0.015, p=.125)$. However, ADC value of cerebrospinal fluid had significantly relation to age $\left(R^{2}=0.026, p=.042\right)$. Furthermore, ADC value of cerebrospinal fluid was significantly correlated to ADC value of spinal cord $\left(R^{2}=0.141, p\right.$
$=.000)$. The data reported herein are representative, and the $\mathrm{ADC}$ values can be used for reference in future studies and in clinical settings.

Fardo et al. ${ }^{[1]}$ conclude that among subjects with cerebrospinal fluid analyses and genotype data available in the Alzheimer's Disease Neuroimaging Initiative cohort, the hippocampal sclerosis of aging risk gene variants are mostly not found to be associated with cerebrospinal fluid protein changes. Engelborghs ${ }^{[2]}$ indicated the discriminatory power for the differential diagnosis of dementia should be improved using other cerebrospinal fluid biomarkers, especially those that are reflective of the pathology of the non- Alzheimer's disease dementia etiologies. Geoffroy et al. ${ }^{[13]}$ showed spinal cord injury is increasingly affecting the middle-aged and aging populations. Regarding the practical implacability of our research, the present study confirmed the changes of cerebrospinal fluid in the upper neck area with age using DWI. The data reported herein are representative, and the ADC values can be used for reference in future studies and in clinical settings. However, the relationship between neurodegenerative diseases, changes with senility and the changes in cerebrospinal fluid using DWI had not been brought out clearly. The author consider that further study is necessary to investigate changes in spinal cord and cerebrospinal fluid with Alzheimer's disease and spinal cord injury using DWI in the upper neck area, furthermore, the research can help predict them. 


\section{Conclusions}

The authors investigated changes in spinal cord and cerebrospinal fluid with age using DWI in the upper neck area. The present study confirmed the changes in cerebrospinal fluid with age using DWI in the upper neck area. The data reported herein are representative, and the ADC values can be used for reference in future studies and in clinical settings.

\section{CONFlicts of INTEREST Disclosure}

There are no conflicts of interest in relation to our article.

\section{REFERENCES}

[1] Fardo DW, Katsumata Y, Kauwe JS, et al. CSF protein changes associated with hippocampal sclerosis risk gene variants highlight impact of GRN/PGRN. Exp Gerontol. 2017; 90: 83-89. PMid:28189700 https://doi.org/10.1016/j.exger.2017.01.025

[2] Engelborghs S. Clinical indications for analysis of Alzheimer's disease CSF biomarkers. Rev Neurol. 2013; 169: 709-14. PMid:24016466 https://doi.org/10.1016/j.neurol. 2013. 07.024

[3] Querin G, El Mendili MM, Lenglet T, et al. Spinal cord multiparametric magnetic resonance imaging for survival prediction in amyotrophic lateral sclerosis. Eur J Neurol. 2017 Jun 6. PMid:28586096 https : //doi.org/10.1111/ene.13329

[4] Sakamoto J, Sasaki Y, Otonari-Yamamoto M, et al. Comparison of various methods for quantification of apparent diffusion coefficient of head and neck lesions with HASTE diffusion-weighted MR imaging. Oral Surg Oral Med Oral Pathol Oral Radiol. 2012; 114: 266-76. PMid:22769413 https://doi.org/10.1016/j.00oo.2012.03 .015

[5] Ryoo I, Kim JH, Choi SH, et al. Squamous cell carcinoma of the head and neck: comparison of diffusion-weighted MRI at b-values of 1,000 and 2,000 s/mm $\mathrm{mm}^{2}$ to predict response to induction chemotherapy. Magn Reson Med Sci. 2015; 14: 337-45. PMid:26104081 https://doi.org/10.2463/mrms.2015-0003

[6] Li S, Cheng J, Zhang Y, et al. Differentiation of benign and malignant lesions of the tongue by using diffusion-weighted MRI at 3.0T. Dentomaxillofac Radiol. 2015; 44:20140325. PMid:25823772 https://doi.org/10.1259/dmfr. 20140325
[7] Sakamoto J, Yoshino N, Okochi K, et al. Tissue characterization of head and neck lesions using diffusion-weighted MR imaging with SPLICE. Eur J Radiol. 2009; 69: 260-8. PMid:18023549 https://doi.org/10.1016/j.ejrad.2007.10.008

[8] Abdel Razek AA, Gaballa G, Elhawarey G, et al. Characterization of pediatric head and neck masses with diffusion-weighted MR imaging. Eur Radiol. 2009; 19: 201-8. PMid:18704436 https: //doi.org/10.1007/s00330-008-1123-6

[9] Schakel T, Hoogduin JM, Terhaard CH, et al. Diffusion weighted MRI in head-and-neck cancer: geometrical accuracy. Radiother Oncol. 2013; 109: 394-7. PMid:24183864 https ://doi.org/10.1 016/j.radonc. 2013.10.004

[10] Kato H, Fujimoto K, Matsuo M, et al. Usefulness of diffusionweighted MR imaging for differentiating between Warthin's tumor and oncocytoma of the parotid gland. Jpn J Radiol. 2017; 35: 78-85. PMid:28074380 https : //doi.org/10.1007/s11604-016-060 8-5

[11] Helenius J, Soinne L, Perkio J, et al. Diffusion-weighted MR imaging in normal human brains in various age groups. AJNR Am J Neuroradiol. 2002; 23: 194-9. PMid:11847041

[12] Newman SD, Li C, Krause JS. Social isolation after spinal cord injury: indicators from the longitudinal aging study. Rehabil Psychol. 2016; 61: 408-16. PMid:27831732 https ://doi.org/10.1037/ rep0000112

[13] Geoffroy CG, Meves JM, Zheng B. The age factor in axonal repair after spinal cord injury: a focus on neuron-intrinsic mechanisms. Neurosci Lett. 2016. PMid:27818358 